\title{
BMJ Open Cross-sectional surveys of the amount of sugar, energy and caffeine in sugar- sweetened drinks marketed and consumed as energy drinks in the UK between 2015 and 2017: monitoring reformulation progress
}

\author{
Kawther M Hashem, Feng J He, Graham A MacGregor
}

To cite: Hashem KM, He FJ, MacGregor GA. Cross-sectional surveys of the amount of sugar, energy and caffeine in sugarsweetened drinks marketed and consumed as energy drinks in the UK between 2015 and 2017: monitoring reformulation progress. BMJ Open 2017;7:e018136. doi:10.1136/ bmjopen-2017-018136

\section{- Prepublication history and} additional material for this paper are available online. To view these files, please visit the journal online (http://dx.doi. org/10.1136/bmjopen-2017018136).

Received 8 June 2017 Revised 3 October 2017 Accepted 18 October 2017
Check for updates

(c) Author(s) (or their employer(s)) 2017. Re-use permitted under CC BY. Published by BMJ.

Wolfson Institute of Preventive Medicine, Barts and The London School of Medicine and Dentistry, Queen Mary University of London, London, UK

Correspondence to Kawther M Hashem; k.hashem@qmul.ac.uk

\section{ABSTRACT}

Objectives To investigate the sugar, energy and caffeine content of sugar-sweetened drinks marketed and consumed as energy drinks available in the UK. Study design We carried out a cross-sectional survey in 2015 and 2017 of energy drinks available in the main UK retailers.

Methods The sugar (sugars $\mathrm{g} / 100 \mathrm{~mL}$ ), energy (kcal/100 mL), caffeine $(\mathrm{mg} / 100 \mathrm{~mL}$ ) and serving size were collected from product packaging and nutrition information panels of energy drinks available in the nine main UK grocery retailers, three health and beauty retailers and one convenience store.

Results The number of formulations (per $100 \mathrm{~mL}$ ) and number of products (per serving) have fallen (from 75 to 49 and from 90 to 59) between 2015 and 2017, respectively. Energy drinks surveyed showed a $10 \%$ reduction in sugar, from 10.6 to $9.5 \mathrm{~g} / 100 \mathrm{~mL}$ $(P=0.011)$ and a $6 \%$ reduction in energy content $(P=0.005)$ per $100 \mathrm{~mL}$ between 2015 and 2017. The average caffeine content of energy drinks, with a warning label, has remained high at $31.5 \pm 0.9$ in 2015 and $31.3 \pm 1.0 \mathrm{mg} / 100 \mathrm{~mL}$ in 2017. Despite there being reductions, sugar, energy and caffeine content remain at concerning levels in 2017.

Conclusions To reduce the harmful impact of energy drinks, further reduction in sugar and a reduction in caffeine by reformulation are urgently needed. Other measures such as ban on the sale of energy drinks to children and smaller product sizes should also be explored, while warning labels should be kept. A reduction in sugar, energy and caffeine content and overall energy drinks consumption could be beneficial in reducing sugar, energy and caffeine intake of consumers of energy drinks.

\section{INTRODUCTION}

In July 2015, the Scientific Advisory Committee on Nutrition (SACN) recommended that average free sugars (sugar) intake, across the UK population, should not exceed $5 \%$ of total energy intake. ${ }^{1}$ This is in line with
Strengths and limitations of this study

- This paper for the first time investigates and documents the sugar, energy and caffeine content of products marketed as energy drinks sold in the UK.

- The results demonstrate that the amount of sugar and energy has fallen, without technical issues, while caffeine levels remain high.

- This paper shows that serving sizes of energy drinks are large and should be reduced.

- The study was based on the levels provided on energy drinks packaging labels in store; hence, we relied on the accuracy of the data provided on the label.

the World Health Organisation's conditional new guideline on sugar intake. ${ }^{2}{ }^{3}$ SACN also advised that consumption of sugar-sweetened drinks, including energy drinks, should be minimised in children and adults, ${ }^{1}$ because high intake of sugar is contributing to obesity, type 2 diabetes and dental caries, ${ }^{3-11}$ major public health problems in the $\mathrm{UK},{ }^{12-19}$ with significant healthcare costs. ${ }^{20}$

The average intakes in 2014 of sugar exceeded recommendations in all age groups. $^{21}$ The mean sugar intake in adults was $60 \mathrm{~g}$ per day and contributes to $12 \%$ of daily energy intake. In children the average sugar intake was $54 \mathrm{~g}(13 \%)$ per day in 4-10 year olds and $73 \mathrm{~g}$ (15\%) per day in 11-18 year olds. $^{21}$

Soft drinks are the main contributor of sugar intake in children (4-10 years) and teenagers (11-18 years) as well as the second main contributor in adults (18-64 years), contributing to $30 \%, 40 \%$ and $25 \%$ of sugar intake, respectively. ${ }^{21}$ Within soft drinks, energy drinks are a booming subcategory. ${ }^{22-25}$ 
Products described as 'energy drinks' by the industry are typically glucose-based energy drinks: functional or stimulation energy drinks which claim a particular energy boost from caffeine, guarana, taurine, ginseng or other herbs or some combination of these ingredients, which are known to have stimulant properties and are distinct from sports drinks (which are often described as 'sports', 'isotonic' or 'hypotonic' and 'hypertonic'). ${ }^{22} 26$ Besides the health concerns around sugar content, the high levels of caffeine in some energy drinks are associated with chronic sleep loss, addiction/dependence, withdrawal and intoxication. ${ }^{26-29}$

In the UK, sales of energy drinks have increased by $155 \%$ between 2006 and 2014, from 235 to 600 million $\mathrm{L}$, with an average per capita consumption of $9.4 \mathrm{~L}$ in $2014 .^{30}$ The leading brands' shares in the UK energy drinks market, by value in 2013-2014, were Red Bull $(25 \%)$, own label (12\%), Monster (10\%), Relentless $(6 \%)$, Rockstar $(5 \%)$, Mountain Dew $(2 \%)$, Boost $(2 \%)$ and Emerge (2\%). ${ }^{31}$

Energy drinks consumption in the UK is a growing problem, particularly among children and teenagers. In 2011, a study by the European Food Safety Authority found young people in the UK consumed more energy drinks than in other EU countries $(3.1 \mathrm{~L}$ per person per month, compared with $2 \mathrm{~L}$ ) ${ }^{32}$ and market research data suggest a potential increase in purchase among children aged $10-14$ years. ${ }^{31}$

The increase in consumption and popularity of energy drinks has raised concerns among the scientific community, governments and the general public about the health effects of these products, particularly among children and adolescents. ${ }^{26} 3334$ There have been two policies to tackle sugar and caffeine content of energy drinks. In terms of sugar content, a two-tiered Soft Drinks Industry Levy (SDIL) on the production and importation of sugar-sweetened drinks, including energy drinks, will be introduced in $2018 .^{35}$ The policy is intended to drive product reformulation and lower sugar consumption. Reformulation is commonly described as efforts by the manufacturer to lower the 'unhealthy' components (eg, saturated fat, trans fat, sugar, salt) of a product at the time of production, without worsening the profile of other ingredients (eg, increasing calorie content). ${ }^{36}$ The reformulated products become a replacement of an existing product (eg, the same brand of energy drink with less sugar). The SDIL aims to incentivise manufacturers of sugar-sweetened drinks with more than $8 \mathrm{~g}$ of sugar, per $100 \mathrm{~mL}$, to reduce the levels to below $8 \mathrm{~g}$ and pay a lower tax rate and manufacturers of drinks with more than $5 \mathrm{~g}$ of sugar per $100 \mathrm{~mL}$ and to lower the sugar levels to less than $5 \mathrm{~g}$ and pay no tax. ${ }^{35}$

In terms of caffeine content, the EU Food Information Regulation requires specific labelling for high caffeine drinks (over $150 \mathrm{mg} / \mathrm{L}$ ). ${ }^{37}$ The warning states that the product is not recommended for children. However, these products can be easily purchased and consumed by children.
This cross-sectional survey has been conducted to document levels of sugar and energy in energy drinks, as well as caffeine in the UK. The data available to monitor the energy drinks market, including whether reformulation is taking place, are generally the preserve of companies and not in the public domain. The main purpose of this research was to (1) report the variability in sugar and energy content in 2015 and 2017, (2) assess the sugar content in relation to the UK's new daily recommendation for sugar intake and by energy drinks brands, (3) quantify the levels of caffeine in energy drinks and determine the products on the market with the back of pack high-caffeine warning, (4) assess the number of products that will be taxed based on the criteria suggested in the SDIL $^{35}$ and (5) evaluate reformulation of energy drinks.

\section{METHODS}

The data were collected from product packaging and nutrient information panels in January 2015 and January 2017. The survey was designed as a comprehensive survey of all energy drinks available in a snapshot in time, using one large outlet for each of the nine main grocery retailers, three health and beauty retailers and one convenience store. This study used the same study design and procedures as reported in our previous work on carbonated sugarsweetened drinks, which excluded energy drinks. ${ }^{38}$

\section{Definition}

Energy drinks were defined as any drink with 'energy', 'energise', 'energiser', 'caffeine' and 'stimulation' in the product name or description, for example, Red Bull Energy Drink, Monster Energy Drink, Relentless Origin Energy Drink and Tropicana Energy Mango and Guava with passion fruit or products with high-caffeine warning label including products not described as 'energy drinks' (such as Mountain Dew).

Since the focus of this study is on product reformulation, products labelled 'zero' or 'light' or 'no added sugar' were excluded. We also excluded products described solely as 'sports' drinks, which consist primarily of carbohydrates and electrolytes and are intended for athletes to rehydrate after exercise, for example, 'Lucozade Sports'. ${ }^{22}$ However, 'Lucozade Energy' was included.

\section{Data collection}

For each energy drink, the data collected included the company name, product name, pack weight, serving size, sugars $(\mathrm{g})$, energy (kcal) and caffeine $(\mathrm{mg})$ per $100 \mathrm{~mL}$ and per serving. Where data were not available per serving, it was calculated from pack size and per $100 \mathrm{~mL}$ data. Caffeine content was only collected in a subsample of the 2015 products.

Where products only labelled 'carbohydrate' content in 2015 but labelled 'sugars' content in 2017 and the content of all nutrients and ingredients were the same, it was assumed that the sugar content from 2015 was the same as 2017 (applied to only one product). 
The data were double checked after entry and a further $5 \%$ of entries were checked against the original source in a random selection of products by the lead author.

\section{Stores}

Data were collected from each of the major UK grocery retailers in store (Aldi, Asda, Lidl, Marks and Spencer, Morrisons, Sainsbury's, Tesco, The Co-operative and Waitrose), which altogether hold $93.2 \%$ of the grocery market share in the UK. ${ }^{39}$ Three health and beauty retailers (Boots, Superdrug and Holland and Barrett) and one convenience store (Costcutter) were also included since they sell a wide variety of branded energy drinks.

\section{Analysis}

Per $100 \mathrm{~mL}$

Some brands sell the same formulation in different serving sizes. Therefore, the $100 \mathrm{~mL}$ data only included an example of one formulation regardless of the different serving sizes.

\section{Per serving}

The per-serving data included all the different serving sizes available apart from $1 \mathrm{~L}$ bottles. One-litre products were excluded from the per-serving analysis since it was deemed that the industry standardised serving of $250 \mathrm{~mL}$ was too little and that consumers are likely to overconsume. Any product with up to $500 \mathrm{~mL}$ can or bottle size was considered as one serving, regardless of what is stated on the packaging as a serving size for example, often a $500 \mathrm{~mL}$ bottle is split into two servings, but we consider that most consumers drink these drinks as one serving.

\section{Caffeine}

Separate analysis was conducted on the products with the high-caffeine warning label (over $150 \mathrm{mg} / \mathrm{L}$ ).

\section{High, medium and low criteria for sugars content}

The sugar content was compared with the UK front of pack colour-coded labelling for drinks. Portion size criteria applied to portion/serving sizes greater than $150 \mathrm{~mL}$. Colour coding is based on the following front of pack colour-coded nutrition labelling criteria (sugars: $\mathrm{red} / \mathrm{high}>13.5 \mathrm{~g} /$ portion or $>11.25 \mathrm{~g} / 100 \mathrm{~mL}$, amber $/$ medium $>2.5$ to $\leq 11.25 / 100 \mathrm{~mL}$, green/low $\leq 2.25 \mathrm{~g} / 100 \mathrm{~mL}) .{ }^{40}$

In addition to the above analyses, the sugar content was compared with the UK's recommendation for sugar intake for adults $(30 \mathrm{~g} /$ day) and children aged 7-10years $(24 \mathrm{~g} /$ day $) .{ }^{40}$ The highest energy-containing products were compared with women's daily energy intake (2000 kcal). ${ }^{41}$ Also, we assessed the number of products that will be taxed based on the criteria suggested in the SDIL. ${ }^{35}$

\section{Statistical analysis}

Comparison among products within each survey

Independent samples Mann-Whitney U Test was used to compare the levels of sugar between supermarket own label and branded products.
Comparison of the same products between the 2 years

For the purpose of assessing reformulation, only the products with data available in both surveys were included in this analysis. Paired t-test was used to examine whether there was a significant change in the sugar and energy content of energy drinks from 2015 to 2017.

Data are reported as mean, SD, range as indicated. Significance in all tests carried out was deemed significant as being $\mathrm{P}<0.05$. All data were analysed using SPSS V.22.

\section{RESULTS}

\section{Sugar, energy and caffeine content per $100 \mathrm{~mL}$ in 2015 and} 2017

A total of 75 and 49 energy drinks met the per $100 \mathrm{mLinclu}$ sion criteria in 2015 and 2017, respectively. The average sugar content was $10.6 \pm 2.9 \mathrm{~g}$ and $9.7 \pm 3.0 \mathrm{~g} / 100 \mathrm{~mL}$, with a large variation in sugar content between different energy drinks ranging from 1.9 to $15.9 \mathrm{~g}$ and 2.1 to $16.0 \mathrm{~g} / 100 \mathrm{~mL}$ in 2015 and 2017 , respectively (table 1 ). There were no significant differences in sugar content between supermarket own label and branded products in $2015(\mathrm{P}=0.397)$ and $2017(\mathrm{P}=0.245)$. The product with the highest and lowest sugar content per $100 \mathrm{~mL}$ in 2015 and 2017 are highlighted in table 2.

The average energy content in energy drinks was $47 \pm 13 \mathrm{kcal} / 100 \mathrm{~mL}$ ranging from 10 to $70 \mathrm{kcal} / 100 \mathrm{~mL}$ in 2015 and $44 \pm 13 \mathrm{kcal} / 100 \mathrm{~mL}$, ranging from 10 to 70 $\mathrm{kcal} / 100 \mathrm{~mL}$ in 2017 (table 1). There were no significant differences in energy content between supermarket own label and branded products in $2015(\mathrm{P}=0.872)$ and 2017 $(\mathrm{P}=0.113)$.

Among all of the manufacturers with three or more formulations of energy drinks in 2015, Rockstar and Lucozade product ranges contained the highest average sugar and energy per $100 \mathrm{~mL}$, respectively (table 3). However, in 2017 the Rockstar product range contained the highest average sugar and energy content per $100 \mathrm{~mL}$ (table 3), which suggests Lucozade have been reformulating their products.

Since not all 'energy drinks' have a high-caffeine content, we analysed the caffeine, sugar and energy content of the products with the warning label separately. A total of 23 and 39 energy drinks formulations had caffeine content labelled on pack in 2015 and 2017 (there may have been more that were labelled but not all were collected in 2015). The average caffeine content in energy drinks was $30.7 \pm 2.9$ in 2015 and $31.6 \pm 0.8 \mathrm{mg} / 100 \mathrm{~mL}$ in 2017 (table 1). The levels of sugar, energy and caffeine were similar to the levels in the full sample of energy drinks.

\section{Sugar, energy and caffeine content per serving in 2015 and 2017}

A total of 90 and 59 energy drinks products met the inclusion criteria in 2015 and 2017, respectively (table 4). The total number of products available has fallen between 2015 and 2017. The total number of products analysed 


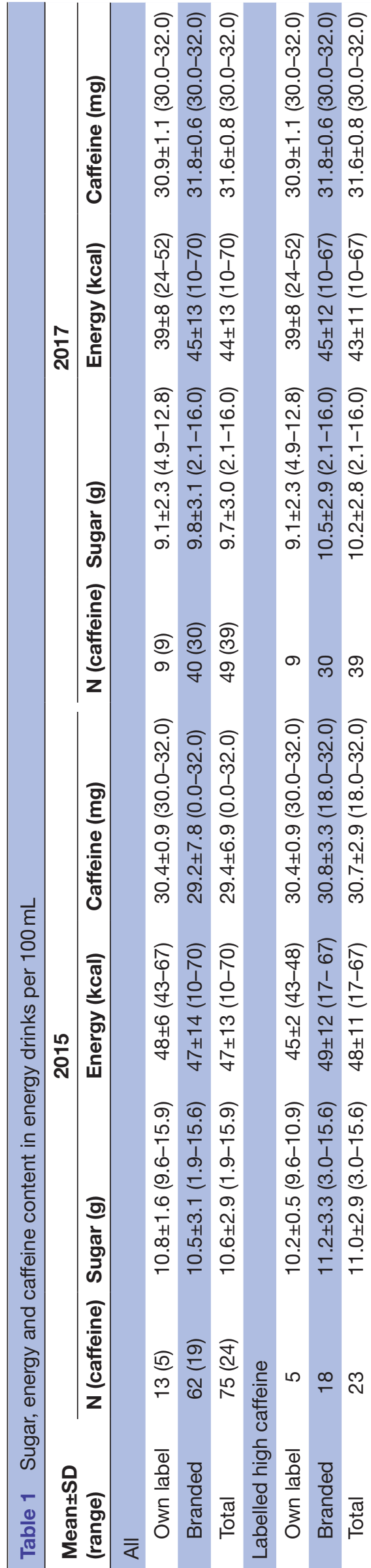

per serving is different to the per $100 \mathrm{~mL}$ data because some brands sell the same formulation in different serving sizes. The serving data included all the different serving sizes available apart from $1 \mathrm{~L}$ bottles. The serving size varied from 150 to $500 \mathrm{~mL}$ in 2015 and 250 to $500 \mathrm{~mL}$ in 2017 . Most products were in a $500 \mathrm{~mL}$ can/bottle $(42 \%$ in 2015 and $47 \%$ in 2017).

The average sugar content in energy drinks was high $41.1 \pm 17.9$ in 2015 and $38.5 \pm 18.2 \mathrm{~g} /$ serving in 2017 (table 4), more than the entire maximum daily recommendation for sugar intake in the UK for an adult $(30 \mathrm{~g})$. Indeed, $59 \%$ of products in 2015 and $54 \%$ in 2017 exceeded the maximum UK's recommendation for sugar intake per serving for an adult $(30 \mathrm{~g} /$ day $)$. Additionally, $86 \%$ in 2015 and $78 \%$ in 2017 of products exceeded the maximum daily recommendation for sugar intake for a child aged 7-10 years ( $24 \mathrm{~g} /$ day). About $96 \%$ and $95 \%$ would receive a 'red' (high) label for sugars per serving (>13.5 g/serving) in 2015 and 2017 , respectively.

The serving size was significantly larger in branded versus supermarket own label products in 2015 ( $\mathrm{P}=0.003)$ and $2017(\mathrm{P}=0.003)$, and as a result, the branded products contained on average higher levels of sugar compared with supermarket products per serving in 2015 ( $\mathrm{P}=0.028)$ and $2017(\mathrm{P}=0.026)$ (figure 1 and table 4).

The average energy content in energy drinks was $185 \pm 81 \mathrm{kcal}$ and $176 \pm 76 /$ serving in 2015 and 2017, respectively. There was a large variation in energy content between different energy drinks ranging from 50 to 350 and 50 to $335 \mathrm{kcal} /$ serving in 2015 and 2017 , respectively (figure 2 and table 4 ).

The energy drink products with the highest energy content in 2015 and 2017 can contribute up to 17\%-17.5\% of a woman's daily energy intake (2000 kcal). ${ }^{41}$

A total of 22 and 43 energy drinks formulations had high-caffeine labels on pack (table 4) in 2015 and 2017, respectively.

\section{Soft drink industry levy in 2017}

A total of 36 products (73\%) would be taxed at the higher SDIL rate $(>8 \mathrm{~g} / 100 \mathrm{~mL})$, nine products $(18 \%)$ at the lower rate $(8-5 \mathrm{~g} / 100 \mathrm{~mL})$ and four products $(8 \%)$ would not be taxed $(<5 \mathrm{~g} / 100 \mathrm{~mL}) .^{35}$

\section{Comparison of the same products between the 2 years}

The overall number of energy drinks formulations has decreased between 2015 and 2017, from 75 to 49 products.

\section{Reformulation}

There were 30 products surveyed repeatedly in 2015 and 2017. The average sugar content per $100 \mathrm{~mL}$ for these products was $10.6 \pm 3.2 \mathrm{~g}$ in 2015 and $9.5 \pm 3.3 \mathrm{~g}$ in 2017 $(\mathrm{P}=0.011$ for comparison between the 2 years). This represents a reduction of $10 \%$. The sugar content has fallen in 12 products, remained the same in 16 and has increased in 2. The average energy content per $100 \mathrm{~mL}$ was $47 \pm 14 \mathrm{kcal}$ in 2015 and $44 \pm 15 \mathrm{kcal}$ in 2017 , $(\mathrm{P}=0.005$ 
Table 2 Highest and lowest sugar energy drink per $100 \mathrm{~mL}$ in 2015 and 2017

\begin{tabular}{llcclcc} 
& \multicolumn{2}{c}{2015} & & & \multicolumn{2}{c}{2017} \\
\cline { 2 - 3 } \cline { 5 - 6 } Highest & Product name & Sainsbury's Orange Energy Drink & 15.9 & & $\begin{array}{l}\text { AG Barr-Rockstar Punched } \\
\text { Energy+Guava Tropical Guava Flavour }\end{array}$ \\
Lowest & Monster Rehab Green Tea Energy & 1.9 & & $\begin{array}{l}\text { Monster Rehab } \\
\text { Tea+Still Lemonade+Energy }\end{array}$ \\
\hline
\end{tabular}

for comparison between the 2 years) representing a $6 \%$ reduction.

There were 12 products surveyed repeatedly in 2015 $(31.5 \pm 0.9)$ and $2017(31.3 \pm 1.0 \mathrm{mg} / 100 \mathrm{~mL})$ displaying the high caffeine warning label. The caffeine content of these products stayed the same, apart from one product, where the caffeine content was reduced, from $32 \mathrm{mg}$ to $30 \mathrm{mg}$.

Note that these averages are slightly different from those when all products were included in each year, and this trend analysis reflects reductions made in the same products rather than the overall products available, giving a better reflection of reformulation, for a full list of products refer to online supplementary file.

\section{DISCUSSION}

These cross-sectional surveys have documented the levels of sugar, energy and caffeine in energy drinks in the UK between 2015 and 2017, a topic which has not been previously documented for easy access by researchers and policy-makers. It will allow for evaluation of trends in the energy drinks market in the future.

The surveys have shown early changes in the energy drinks market. Formulations (per $100 \mathrm{~mL}$ ) and number of products (per serving) have fallen between 2015 and 2017. This may be due to the pressure on the soft drinks industry to reduce sugary drinks offerings. ${ }^{42}$ Furthermore, the energy drinks surveyed showed a small but statistically significant reduction in sugar content; this is likely due to the 12 products which have reduced sugar content between 2015 and 2017, probably as a result of reformulation due to the impending SDIL. ${ }^{35}$ Manufacturers of the reduced products have either only reduced sugar or have alternatively reduced sugar and replaced it with non-caloric sweeteners without changing the product name, for example, by calling the product 'light' and so on. Given the volume consumed, ${ }^{22}$ even small reductions in sugar content of energy drinks would have a significant impact on sugar and energy intake among regular consumers of energy drinks. $^{43}$

Table 3 Sugar and energy content in energy drinks by manufacturer per $100 \mathrm{~mL}$

\begin{tabular}{|c|c|c|c|c|c|}
\hline \multicolumn{3}{|c|}{2015} & \multicolumn{3}{|c|}{2017} \\
\hline Manufacturer & $\mathbf{N}$ & Sugar $(g)$ mean $\pm S D$ (range) & Manufacturer & $\mathbf{N}$ & Sugar $(g)$ mean $\pm S D$ (range) \\
\hline Rockstar & 8 & $14.1 \pm 1.1(12.1-15.6)$ & Rockstar & 5 & $14.2 \pm 1.5(12.0-16.0)$ \\
\hline Sainsbury's & 4 & $12.1 \pm 2.6(10.6-15.9)$ & Red Bull & 3 & $11.0 \pm 0.0(11.0-11.0)$ \\
\hline Relentless & 5 & $10.6 \pm 0.6(10.1-11.6)$ & Lidl & 5 & $10.2 \pm 1.7(8.8-12.8)$ \\
\hline $\mathrm{KX}$ & 3 & $10.2 \pm 0.2(10.1-10.5)$ & Monster & 8 & $8.5 \pm 2.8(2.1-11.0)$ \\
\hline Little Miracles & 3 & $6.4 \pm 0.2(6.2-6.6)$ & Little Miracles & 3 & $5.7 \pm 0.5(5.1-6.1)$ \\
\hline Monster & 7 & $6.4 \pm 4.2(1.9-11.0)$ & & & \\
\hline Manufacturer & $\mathbf{N}$ & $\begin{array}{l}\text { Energy (kcal) mean } \pm \text { SD } \\
\text { (range) }\end{array}$ & Manufacturer & $\mathbf{N}$ & $\begin{array}{l}\text { Energy (kcal) mean } \pm \text { SD } \\
\text { (range) }\end{array}$ \\
\hline Sainsbury's & 4 & $53 \pm 9(48-67)$ & Red Bull & 3 & $45 \pm 1(45-46)$ \\
\hline Asda & 4 & $46 \pm 2(43-48)$ & Relentless & 5 & $46 \pm 10(31-58)$ \\
\hline Relentless & 5 & $44 \pm 2(43-48)$ & Lidl & 5 & $42 \pm 7(36-52)$ \\
\hline $\mathrm{KX}$ & 3 & $44 \pm 2(42-46)$ & Monster & 8 & $37 \pm 12(10-48)$ \\
\hline Monster & 7 & $29 \pm 18(10-48)$ & Little Miracles & 3 & $25 \pm 2(23-26)$ \\
\hline Little Miracles & 3 & $27 \pm 1(26-27)$ & & & \\
\hline
\end{tabular}




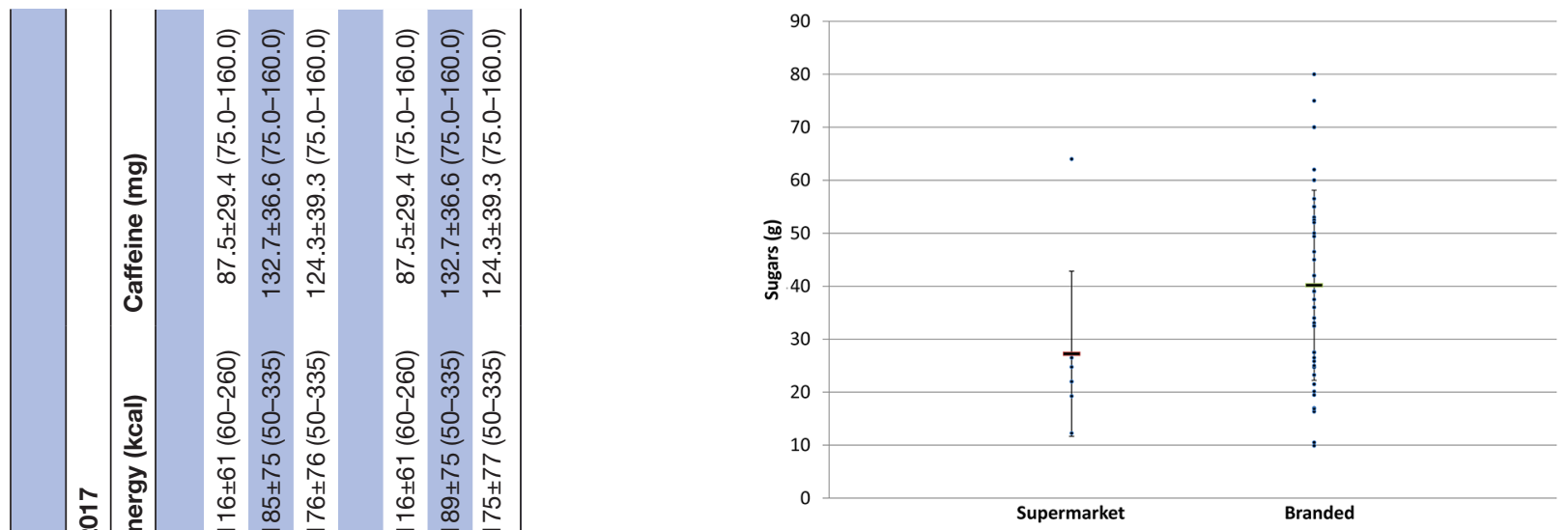

Figure 1 Sugar content in supermarket and branded energy drinks (g/serving) in 2017.

This survey suggests the early success of the impending SDIL. Even though the SDIL is yet to come in, manufacturers have started to reformulate their products in advance to avoid paying the levy. However, we are yet to see if the SDIL will have an impact on overall consumption of energy drinks by reducing sales. ${ }^{44}$ Other countries have imposed taxes on soft drinks, including energy drinks, and have seen reductions in sales. ${ }^{45} 46$

Despite this, sugar content remains at concerning levels, 95\% would receive a 'red' (high) label for sugars per serving in 2017. There was also a large variation in sugar content between different energy drinks ranging from 2.1 to $16.0 \mathrm{~g} / 100 \mathrm{~mL}$, which suggests further reductions are possible.

As well as the concerns around the sugar and energy content of energy drinks, there are also concerns about caffeine levels, particularly in the products labelled as high caffeine. In 2017, average caffeine content in energy drinks was $124.3 \pm 39.3 \mathrm{mg} /$ serving among the 43 products labelled, almost equivalent to two cups of coffee or four cans of cola. ${ }^{37}$ There is also some evidence to suggest that the caffeine content increases sugar-sweetened drinks consumption further and therefore sugar intake too. ${ }^{47}$ Since children and teenagers are the main consumers of energy drinks,

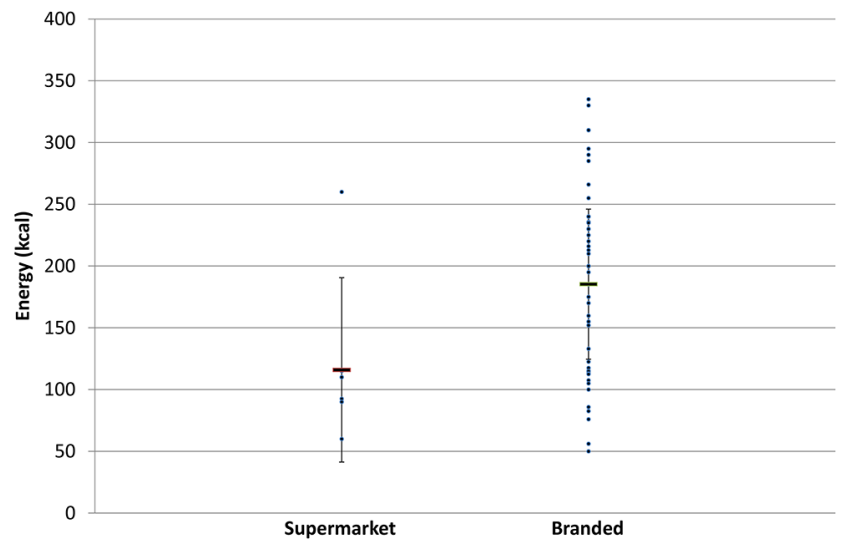

Figure 2 Energy content in supermarket and branded energy drinks (g/serving) in 2017. 
manufacturers should consider reducing levels of caffeine-again through reformulation. The removal of caffeine also allows for the removal of $10.3 \%$ of sugar without affecting taste, which has the potential to reduce body weight of adults by $0.6 \mathrm{~kg}$, without any change in sugar-sweetened drinks consumption. ${ }^{48}$

It important to note that not all manufacturers label the amount of caffeine on their energy drinks, and this is likely because their products do not exceed the cut-off for adding the warning label. ${ }^{37}$ Among the manufacturers that do, a warning is stated on the pack, acknowledging the potential danger these products can pose to children. However, these products can be easily purchased and consumed by children. Perhaps the UK should consider restrictions like other countries. In Lithuania, sales of energy drinks (containing at least $150 \mathrm{mg}$ of caffeine per litre) are banned to under 18 years of age. ${ }^{49}$ A similar law applies in Sweden where sales of energy drinks are banned to children under 15 years of age and sales of some energy drinks are restricted to pharmacies. ${ }^{26}$

Furthermore, serving sizes of energy drinks matter since the larger the serving size, the more sugar, energy and caffeine is consumed. Indeed, typical serving sizes of energy drinks are larger than other sugar-sweetened drinks $^{38}$; this survey showed that the most common serving size was $500 \mathrm{~mL}$. The average sugar content in energy drink in both surveys per serving was more than an adult's entire maximum daily recommendation for sugar intake in the UK. Likewise, $86 \%$ in 2015 and $78 \%$ in 2017 of the products exceeded the maximum daily recommendation for sugar intake for a child aged $7-10$ years $\left(24 \mathrm{~g} /\right.$ day). ${ }^{1}$ The products with the highest sugar and energy content per serving could contribute up $17.5 \%$ of a woman's total daily energy intake. Therefore, to reduce the amount of sugar, energy and caffeine consumed from energy drinks, there is scope for introducing restrictions on larger serving sizes ( $500 \mathrm{~mL}$ bottles and cans). This is a growing problem, which must be tackled, particularly since the Grocer recently reported an increase in sales of larger cans of energy drinks on the UK market. ${ }^{23}$

Our study was based on sugar, energy and caffeine content data provided on the available energy drinks packaging labels in store on the dates of collection; hence, we relied on the accuracy of the data provided on the label and the availability of products in store. It is assumed that the manufacturers provide accurate and up-to-date information in line with EU regulations. However, future studies should include sugar and energy content determined through laboratory analysis to achieve a better understanding of the true sugar and energy content and breakdown of the types of sugars. Furthermore, an analysis of what are the best selling products in the UK would allow for an accurate estimate of the potential impact of reformulation.

Also, the data collection process of caffeine content was slightly different in the two surveys. In 2015, caffeine was collected in a subsample of products, since the aim was not to collect caffeine at the time, but the data that were collected were included in the analysis, this may not give a full reflection of caffeine content of all products on the market in 2015 .

Still, the results of this study are relevant and serve to document the sugar, energy and caffeine content of energy drinks sold the in UK, underpinning future studies and providing evidence for the treasury, policy-makers and the soft drinks industry, who are reformulating. ${ }^{5051}$

\section{CONCLUSION}

Factors such as an increase in sales, ${ }^{242530}$ concerning levels of sugar, energy and caffeine (assessed in this study), ease of access, ${ }^{33}$ large serving sizes, as well as limited regulation have created an environment where energy drinks could pose a major threat to public health.

To reduce the impact of energy drinks, sugar (and therefore energy) reformulation should continue and begin regarding caffeine content. Other measures such as a ban on the sale of energy drinks to children should be explored, while warning labels should be kept. Can and bottle sizes of energy drinks should also be decreased to reduce the overall consumption of sugar, energy and caffeine. A reduction in sugar, energy and caffeine content and overall energy drinks consumption could be beneficial in reducing sugar, energy and caffeine intake of consumers of energy drinks.

Contributors $\mathrm{KH}$ conducted the research; $\mathrm{KH}$ and FJH analysed the data; $\mathrm{KH}$ wrote the first draft of the manuscript and all authors contributed to the interpretation of the results and revision of the manuscript and approved the final version. GAM had primary responsibility for the final content.

Competing interests None declared.

Patient consent Obtained.

Provenance and peer review Not commissioned; externally peer reviewed.

Data sharing statement No additional data are available.

Open access This is an open access article distributed in accordance with the Creative Commons Attribution 4.0 Unported (CC BY 4.0) license, which permits others to copy, redistribute, remix, transform and build upon this work for any purpose, provided the original work is properly cited, a link to the licence is given, and indication of whether changes were made. See: https://creativecommons.org/ licenses/by/4.0/.

\section{REFERENCES}

1. PHE. Why 5\%. 2015 https://www.gov.uk/government/uploads/ system/uploads/attachment_data/file/446010/Why_5___The_ Science_Behind_SACN.pdf (accessed 1 Jul 2017).

2. WHO. Guideline: Sugars intake for adults and children. $2015 \mathrm{http}: / /$ apps.who.int/iris/bitstream/10665/149782/1/9789241549028_eng. pdf?ua $=1$ (accessed 1 Jul 2015).

3. Moynihan PJ, Kelly SA. Effect on caries of restricting sugars intake: systematic review to inform WHO guidelines. J Dent Res 2014;93:8-18.

4. SACN. Carbohydrates and health. 2015 https://www.gov.uk/ government/uploads/system/uploads/attachment_data/file/445503/ SACN_Carbohydrates_and_Health.pdf (accessed 1 Dec 2015).

5. Romaguera D, Norat T, Wark PA, et al. Consumption of sweet beverages and type 2 diabetes incidence in European adults: results from EPIC-InterAct. Diabetologia 2013;56:1520-30.

6. de Koning L, Malik VS, Rimm EB, et al. Sugar-sweetened and artificially sweetened beverage consumption and risk of type 2 diabetes in men. Am J Clin Nutr 2011;93:1321-7. 
7. Maki KC, Phillips AK. Dietary substitutions for refined carbohydrate that show promise for reducing risk of type 2 diabetes in men and women. J Nutr 2015;145:159S-63.

8. Feinman RD, Pogozelski WK, Astrup A, et al. Dietary carbohydrate restriction as the first approach in diabetes management: critical review and evidence base. Nutrition 2015;31:1-13.

9. Te Morenga L, Mallard S, Mann J. Dietary sugars and body weight: systematic review and meta-analyses of randomised controlled trials and cohort studies. BMJ 2012;346:e7492.

10. Johnson RK, Appel LJ, Brands M, et al. Dietary sugars intake and cardiovascular health: a scientific statement from the American Heart Association. Circulation 2009;120:1011-20.

11. Xi B, Li S, Liu Z, et al. Intake of fruit juice and incidence of type 2 diabetes: a systematic review and meta-analysis. PLoS One 2014:9:e93471.

12. PHE. UK and Ireland prevalence and trends. 2013. https://www. noo.org.uk/NOO_about_obesity/adult_obesity/UK_prevalence_and trends (accessed 2 Jul 2015).

13. HSCIC. Statistics on obesity physical activity and diet: England 2014. 2014. http://www.hscic.gov.uk/catalogue/PUB13648/Obes-physacti-diet-eng-2014-rep.pdf (accessed Jul 2015)

14. PHE. Adult obesity and type 2 diabetes. 2014. https://www.gov.uk/ government/uploads/system/uploads/attachment data/file/338934/ Adult_obesity_and_type_2_diabetes_.pdf (accessed 2 Jul 2015).

15. HSCIC. National Diabetes Audit. 2008 http://www.hscic.gov. uk/catalogue/PUB02580/nati-diab-audi-07-08-exec-summ.pdf (accessed Jul 2015).

16. Houses-of-Parliament. Sugar and health. 2015. http://www. actiononsalt.org.uk/actiononsugar/Sugar\%20in\%20the\%20news/ 2015/159388.pdf

17. PHE. Dental public health epidemiology programme. Oral health survey of three-year-oldchildren 2013. A report on the prevalence and severity of dental decay. 2012. http://www.nwph.net/ dentalhealth/Oral\%20Health\%205yr\%20old\%20children\%202012\% 20final\%20report\%20gateway\%20approved.pdf (accessed 2 Dec 2015).

18. PHE. Dental public health epidemiology programme. Oral health survey of three-year-oldchildren 2013. A report on the prevalence and severity of dental decay. 2014. http://www.nwph. net/dentalhealth/reports/DPHEP\%20for\%20England\%200H\% 20Survey\%203yr\%202013\%20Report.pdf (accessed 2 Dec 2015).

19. NHS. Executive summary: adult dental health survey. 2009. http:// www.hscic.gov.uk/catalogue/PUB01086/adul-dent-heal-surv-summthem-exec-2009-rep2.pdf (accessed 2 Dec 2015).

20. PHE. Sugar reduction Responding to the challenge. 2014. https:// www.gov.uk/government/uploads/system/uploads/attachment_data/ file/324043/Sugar_Reduction_Responding_to_the_Challenge_26 June.pdf (accessed 1 Jun 2014).

21. PHE. NDNS: results from Years 5 and 6 (combined). 2016. https:// www.gov.uk/government/statistics/ndns-results-from-years-5-and-6combined (accessed 2 Jun 2016)

22. BSDA. Creating New Choices. The 2014 UK Soft Drinks Report. 2014. http://www.britishsoftdrinks.com/write/MediaUploads/ Publications/Revised_BSDA_Annual_Report_2014.pdf (accessed 23 Jun 2015).

23. The-Grocer. Red Bull flies high as full-sugar sales surge. 2017. https://www.thegrocer.co.uk/buying-and-supplying/health/red-bullflies-high-as-full-sugar-sales-surge/550194.article (accessed $30 \mathrm{Ju}$ 2017).

24. Kleiman S, Ng SW, Popkin B. Drinking to our health: can beverage companies cut calories while maintaining profits? Obes Rev 2012;13:258-74.

25. The Grocer. Focus on energy drinks 2015. 2015. http://www. thegrocer.co.uk/reports/category-reports/focus-on-energy-drinks2015/520323. article (accessed 25 Aug 2016).

26. Breda JJ, Whiting SH, Encarnação R, et al. Energy drink consumption in europe: a review of the risks, adverse health effects, and policy options to respond. Front Public Health 2014;2.

27. Owens J. Adolescent Sleep Working GroupCommittee on Adolescence. Insufficient sleep in adolescents and young adults: an update on causes and consequences. Pediatrics 2014;134:e92 $1-\mathrm{e} 932$.
28. Seifert SM, Schaechter JL, Hershorin ER, et al. Health effects of energy drinks on children, adolescents, and young adults. Pediatrics 2011;127:511-28.

29. Reissig CJ, Strain EC, Griffiths RR. Caffeinated energy drinks: a growing problem. Drug Alcohol Depend 2009;99:1-10.

30. BSDA. Association BSDIn: , ed. Changing Tastes. The UK Soft Drinks Annual Report, 2015

31. Mintel. Sports and Energy Drinks - UK - July 2014, 2014.

32. Consortium N-A. Gathering consumption data on specific consumer groups of energy drinks. 2013. http://onlinelibrary.wiley.com/doi/ (accessed 20 Mar 2017).

33. Visram S, Hashem K. Energy drinks: what's the evidence? Food Research Collaboration, 2016.

34. European-Parliament. Schaldemose: "Energy drinks shouldn't have any kind of health claims on them". 2016. http://www.europarl. europa.eu/news/en/news-room/20160613STO31976/schaldemoseenergy-drinks-shouldn (accessed 1 Sep 2017).

35. Gov.uk. Policy paper Soft Drinks Industry Levy. 2016. https://www. gov.uk/government/publications/soft-drinks-industry-levy/softdrinks-industry-levy (accessed July 2017).

36. van Raaij J, Hendriksen M, Verhagen $\mathrm{H}$. Potential for improvement of population diet through reformulation of commonly eaten foods. Public Health Nutr 2009;12:325-30.

37. FSA. High caffeine 'energy' drinks and other foods containing caffeine n.d. https://www.food.gov.uk/science/additives/energydrinks (accessed July 2017).

38. Hashem KM, He FJ, Jenner $\mathrm{KH}$, et al. Cross-sectional survey of the amount of free sugars and calories in carbonated sugar-sweetened beverages on sale in the UK. BMJ Open 2016:6:e010874.

39. Kantar-Worldpanel. Grocery Market Share-Kantar Worldpanel. 2017. http://www.kantarworldpanel.com/en/grocery-market-share/ great-britain (accessed 30 Apr 2016)

40. Department-of-Health. Guide to creating a front of pack (FoP) nutrition label for pre-packed products sold through retail outlets. 2016. https://www.food.gov.uk/sites/default/files/multimedia/pdfs/ pdf-ni/fop-guidance.pdf (accessed $1 \mathrm{Jul}$ 2017).

41. NHS. What should my daily intake of calories be? 2016. http://www. nhs.uk/chq/pages/1126. aspx?categoryid=51 (accessed 1 Jul 2017).

42. PHE. Sugar Reduction The evidence for action. 2015. https://www. gov.uk/government/uploads/system/uploads/attachment_data/file/ 470179/Sugar_reduction_The_evidence_for_action.pdf (accessed 2 Oct 2015).

43. Ma Y, Fj H, Yin Y, et al. Gradual reduction of sugar in soft drinks without substitution as a strategy to reduce overweight,obesity, and type 2 diabetes: a modelling study. Lancet Diabetes Endocrinol 2016;4:105-14

44. Briggs ADM, Mytton OT, Kehlbacher A, et al. Health impact assessment of the UK soft drinks industry levy: a comparative risk assessment modelling study. Lancet Public Health 2017;2:e15-22.

45. WCRF. Use economic tools to address food affordability and purchase incentives. 2016. http://www.wcrf.org/int/policy/ nourishing-framework/use-economic-tools (accessed 11 Aug 2017).

46. Colchero MA, Popkin BM, Rivera JA, et al. Beverage purchases from stores in Mexico under the excise tax on sugar sweetened beverages: observational study. BMJ 2016;352:h6704.

47. Keast RS, Swinburn BA, Sayompark D, et al. Caffeine increases sugar-sweetened beverage consumption in a free-living population: a randomised controlled trial. Br J Nutr 2015;113:366-71.

48. Keast RS, Sayompark D, Sacks G, et al. The influence of caffeine on energy content of sugar-sweetened beverages: 'the caffeine-calorie effect'. Eur J Clin Nutr 2011;65:1338-44.

49. Law EF. Lithuania bans sale of energy drinks to children. 2014. http:// www.eurofoodlaw.com/country-reports/eu-member-states/lithuania/ lithuania-bans-sale-of-energy-drinks-to-children-104098.htm (accessed 1 Jul 2017).

50. Lucozade-Ribena-Suntory. Health and wellbeing n.d. https://www. Irsuntory.com/health-and-wellbeing/ (accessed 1 Jul 2017)

51. Tesco. Tesco reduces sugar content in all own brand soft drinks. 2016. https://www.tescoplc.com/news/news-releases/2016/tescoreduces-sugar-content-in-all-own-brand-soft-drinks (accessed $1 \mathrm{Jul}$ 2017). 